\title{
PENURUNAN KADAR SIANIDA DENGAN PENGOLAHAN SISTIM OKSIDASI PADA INDUSTRI PELAPISAN LOGAM
}

\author{
Oleh :
}

Siti Agustina, Emmy Ratnawati *)

\begin{abstract}
It's common that the waste water from electroplating industry contains heavy metals such as cyanide. Based on this research, reduction of cyanide content from electroplating waste water is conducted by $C N$ and $C N O$ oxidations with sodium hypochlorite as an oxidator. The result of this research shown that the optimum condition for $C N$ oxidations is on $\mathrm{pH} 10.5$, reaction time 6 minutes which resulting $C N$ reduction $98,6 \%$, while the CNO oxidations is on $\mathrm{pH} 8.0$, reaction time 15 minutes. By process of oxidations, coagulations, sedimentations and filtrations the $C N$ content from electroplating waste water can be reduced from $30 \mathrm{mg} / \mathrm{l}$ to $0.004 \mathrm{mg} / \mathrm{l}$ to fulfill waste water quality standard for electroplating industry maximum $0.05 \mathrm{mg} / \mathrm{l}$.
\end{abstract}

\section{Pendahuluan}

Industri pelapisan logam merupakan industri yang mempunyai peranan yang cukup strategis baik dilihat dari aspek sosial maupun aspek teknis. Dengan berkembangnya industri pelapisan logam selain mempunyai dampak positif bagi ekonomi masyarakat dan devisa negara, juga memberikan dampak negatif yaitu masalah, pencemaran yang diakibatkan oleh limbah yang tidak dikelola secara baik dan benar.Air limbah industri pelapisan logam umumnya banyak mengandung logam-logam berat, diantaranya adalah sianida. Logam ini sangat berbahaya bagi kesehatan manusia, karena apabila logam sianida terkonsumsi manusia akan menyebabkan diare, sesak

*) Staf Peneliti

Balai Penelitian Pupuk dan Petrokimia

Balai Besar Industri Kimia. nafas dan dapat menyebabkan kematian. Mengingat sangat bahayanya logam sianida terhadap lingkungan, maka pengolahan limbah cair yang mengandung logam tersebut harus dilakukan secara efektif.

\section{TINJAUAN PUSTAKA}

Senyawa sianida digunakan dalam pelapisan logam atau "electroplating" untuk mengeraskan logam pelapis (hardening) dan untuk mengurangi porositas permukaan logam pelapis. Pada kondisi asam sianida akan terhidrolisa membentuk senyawa toksik, yaitu HCN dengan keseimbangan reaksi sebagai berikut :

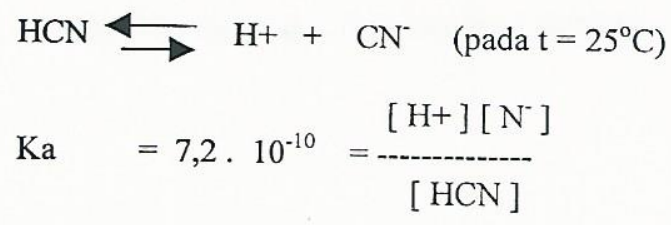


Senyawa sianida yang digunakan dalam proses industri, umumnya dalam bentuk Natrium Sianida $(\mathrm{NaCN})$ atau hidrogen sianida (HCN). Jadi dalam air limbah sianida berada dalam bentuk $\mathrm{CN}^{-}$atau $\mathrm{HCN}$. Penambahan khlor pada suasana alkalis dengan $\mathrm{NaOH}$, akan mengoksidasi sianida $(\mathrm{CN})$ menjadi sianat $\left(\mathrm{CNO}^{-}\right)$, yang mempunyai toksisitas seribu lebih lemah dari sianida. Reaksi oksidasi dengan penambahan khlorin, sebagai berikut :

\section{$\mathrm{NaCN}+\mathrm{Cl}_{2} \rightleftarrows \mathrm{CNCl}+\mathrm{NaCl}$}

Reaksi diatas berjalan lambat, pada $\mathrm{pH}<$ 8 , tetapi pada $\mathrm{pH}>8,5$ reaksi diatas berjalan dengan sempurna setelah 30 menit. Disamping itu reaksi diatas tergantung pula pada temperatur (temperatur $\pm 25^{\circ} \mathrm{C}$ )dan berjalan cepat dengan penambahan khlorin berlebih, dimana CNO- akan tereduksi menjadi gas $\mathrm{N}_{2}$ dengan reaksi sebagai berikut :

$2 \mathrm{NaCNO}+4 \mathrm{NaOH}+3 \mathrm{Cl}_{2} \longrightarrow 2 \mathrm{CO}_{2}+6 \mathrm{NaCl}+\mathrm{N}_{2}+\mathrm{H}_{2} \mathrm{O}$

Meskipun reaksi diatas lambat, tetapi biasanya $\mathrm{pH}$-nya diatur, Hal ini selain untuk mempercepat reaksi, juga untuk mengeliminasi pembentukan $\mathrm{Ncl}_{3}$. Penambahan dosis berlebih, selain menjamin oksidasi sempurna CNO- menjadi $\mathrm{N}_{2}$ dan $\mathrm{CO}_{2}$, juga menjamin oksidasi dengan kehadiran senyawa nitrogen dan besi. Sianida dapat dioksidasi dengan penambahan natrium hypokhlorit, dengan reaksi sebagai berikut :

$\mathrm{NaCN}+\mathrm{NaOCl} \rightarrow \mathrm{NaCNO}+\mathrm{NaCl}$

$2 \mathrm{NaCNO}+3 \mathrm{NaOCl}+\mathrm{H}_{2} \mathrm{O} \longrightarrow 2 \mathrm{NaHCO}_{3}+3 \mathrm{NaCl}+\mathrm{N}_{2} \ldots$ (2)
Natrium hypoklorit $(\mathrm{NaOCl})$ secara dapat digunakan untuk memecah natrium sianida $(\mathrm{NaCN})$, tetapi tidak dapat bekeuntuk limbah yang mengandung besi kompleks dan kobalt tanpa pemanasan dan oksidasi berlanysun sangat lambat bila limbah mengandung atau Hg. Pengolahan air limbah yan mengandung sianida dapat dilakuka dengan sistem batch atau dengan sistar kontinyu. Untuk mencegah pembentula senyawa sianida yang toksik, yaitu $\mathrm{HC}$ sebaiknya air limbah yang mengandun sianida dipisahkan dari air limbah yan mengandung $\mathrm{pH}$ rendah.

\section{BAHAN DAN METODOLOC: PENELITIAN}

\section{A. BAHAN}

- Air limbah dari air pencucian prose pelapisan logam (volume limbah tim variabel $=500 \mathrm{ml}$ )

- $\mathrm{NaOH}$ (Natrium Hidroksida)

- Natrium Hypokhlorit $(\mathrm{NaOCl})$

- Asam sulfat $\left(\mathrm{H}_{2} \mathrm{SO}_{4}\right)$

\section{B. PERALATAN}

- $\mathrm{pH}$ meter

- Alat-alat gelas

- Kertas saring advantec No.5A

- Pengaduk magnetik

- Jar Test

- Stop watch

- Atomic Absorption Spectrophotomenta (AAS)

Metodologi Penelitian 


\section{METODOLOGI PENELITIAN}

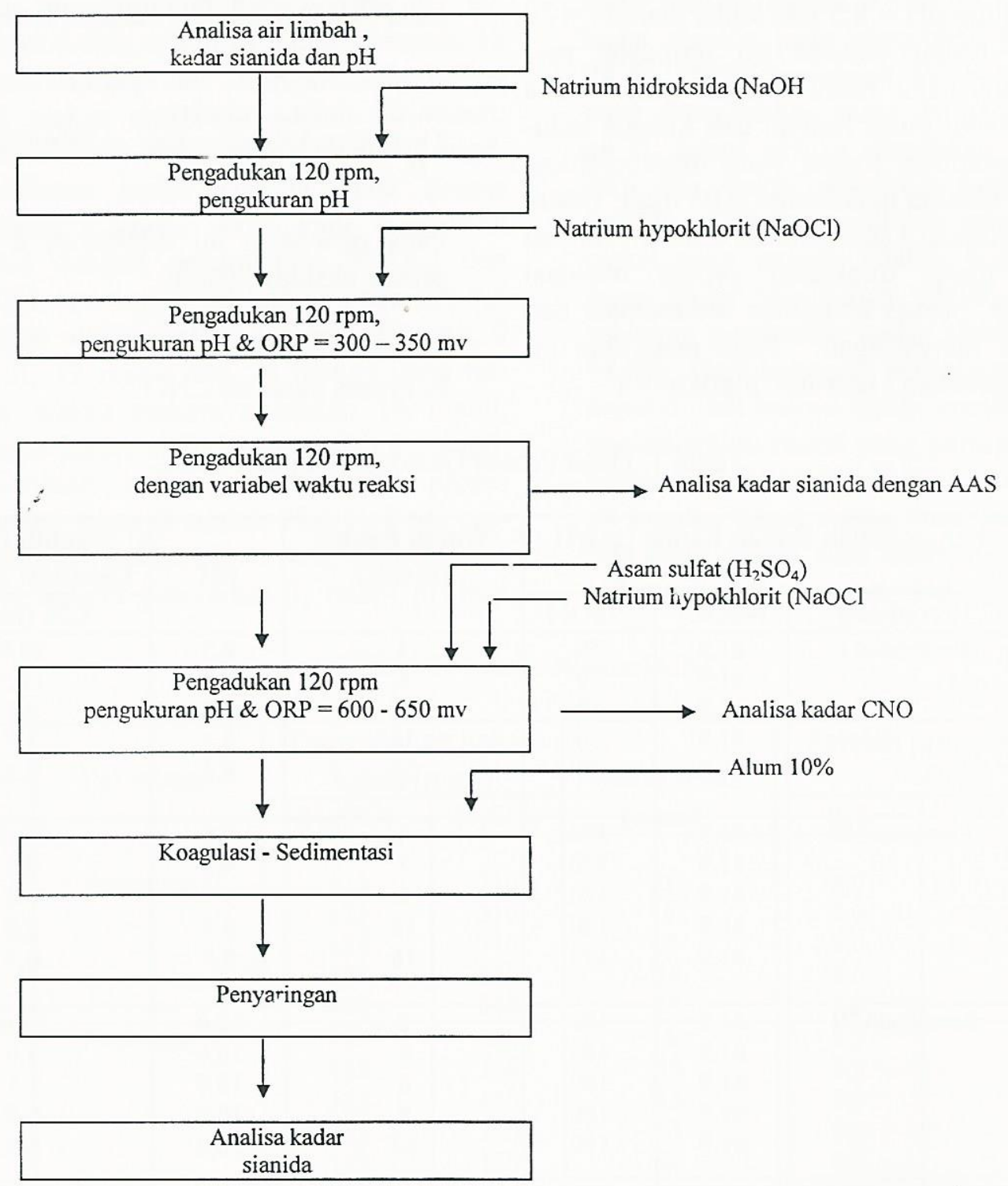




\section{HASIL DAN PEMBAHASAN}

Air limbah yang berasal dari industri pelapisan logam, setelah dianalisa mengandung $\mathrm{pH}=8,5$ dan kadar sianida $=30$ $\mathrm{mg} / \mathrm{l}$. Kadar sianida ini termasuk melampaui baku mutu limbah cair, karena pada baku mutu limbah cair khusus industri pelapisan logam yang diperbolehkan kadar sianida maksimum $0,05 \mathrm{mg} / \mathrm{l}$. Untuk menurunkan kadar sianida didalam limbah cair, maka dilakukan proses oksidasi sianida, proses koagulasi sedimentasi dan proses penyaringan. Pada penelitian ini menggunakan natrium hipokhlorit -
(NaOCl) sebagai oksidator sianida. Natrium hipokhlorit dapat memecah natrium sianida didalam limbah cair melalui proses oksidasi. Ada 2 tahapan reaksi pada oksidasi sianida, sebagai berikut :

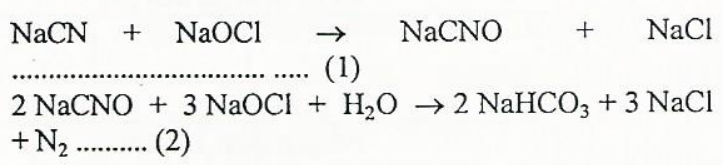

Pada penelitian ini dilakukan 2 tahapan proses oksidasi, yaitu :

1. Proses oksidasi CN

2. Proses oksidasi $\mathrm{CNO}$

Tabel 1. Hasil Proses Oksidasi Sianida

\begin{tabular}{|c|c|c|c|c|c|c|}
\hline No & \multicolumn{3}{|c|}{ Penambahan Bahan Kimia (mg/l) } & \multirow{2}{*}{$\begin{array}{c}\text { Waktu Reaksi } \\
\text { (menit) }\end{array}$} & $\mathrm{pH}$ & $\begin{array}{c}\text { Setelah Proses } \\
\text { Oksidasi Sianida }\end{array}$ \\
\cline { 2 - 4 } & Percobaan & $\mathrm{NaOCl}$ & $\mathrm{NaOH}$ & & & $\mathrm{CN}$ (mg/i) \\
\hline I & Percobaan I & 81,9 & 50 & 4 & 8,5 & 20,0 \\
& & 81,9 & 50 & 8 & 8,5 & 12,5 \\
& & 81,9 & 50 & 12 & 8,5 & 8,5 \\
& & 81,9 & 50 & 16 & 8,5 & 3,7 \\
& & 81,9 & 50 & 20 & 8,5 & 0,5 \\
\hline II & Percobaan II & 81,9 & 120 & 4 & 9,5 & 17,5 \\
& & 81,9 & 120 & 7 & 9,5 & 9,5 \\
& & 81,9 & 120 & 9 & 9,5 & 6,0 \\
& & 81,9 & 120 & 12 & 9,5 & 2,0 \\
& & 81,9 & 120 & 16 & 9,5 & 0,4 \\
\hline III & Percobaan III & 81,9 & 180 & 2 & 10,0 & 23,0 \\
& & 81,9 & 180 & 4 & 10,0 & 8,0 \\
& & 81,9 & 180 & 6 & 10,0 & 1,1 \\
& & 81,9 & 180 & 8 & 10,0 & 0,7 \\
& & 81,9 & 180 & 10 & 10,0 & 0,5 \\
\hline IV & Percobaan IV & 81,9 & 250 & 2 & 10,5 & 17,5 \\
& & 81,9 & 250 & 4 & 10,5 & 0,8 \\
& & 81,9 & 250 & 6 & 10,5 & 0,4 \\
& & 81,9 & 250 & 8 & 10,5 & 0,4 \\
& & 81,9 & 250 & 10 & 10,5 & 0,4 \\
\hline
\end{tabular}


Tabel 1 menunjukkan bahwa pada penelitian ini dilakukan 4 kali percobaan oksidasi sianida. Pada percobaan pertama dengan penambahan $\mathrm{NaOH}$ dan $\mathrm{NaOCl}$ $20 \%$, menunjukkan bahwa pada $\mathrm{pH} 8,5$ dengan waktu reaksi (4 menit, 8 menit, 12 menit, 16 menit dan 20 menit) yang paling baik waktu reaksinya adalah 20 menit, dimana kadar sianidanya adalah $0,5 \mathrm{mg} / \mathrm{l}$. Penurunan kadar sianida pada proses oksidasi I adalah $98 \%$. Pada percobaan kedua dengan penambahan $\mathrm{NaOCl}$ dan $\mathrm{NaOH}$, menunjukkan bahwa pada $\mathrm{pH} 9,5$ dengan waktu reaksi (4 menit, 7 menit, 9 menit, 12 menit dan 16 menit) yang terbaik waktu reaksinya adalah 16 menit, dimana kadar sianidanya adalah $0,4 \mathrm{mg} / \mathrm{l}$. Penurunan kadar sianida pada proses oksidasi tahap II adalah 98,6\%. Pada percobaan III, bahan kimia yang ditambahkan sama dengan percobaan II, tetapi $\mathrm{pH}$ nya dinaikkan yaitu $\mathrm{pH}$ 10,0 dan waktu reaksi ( 2 menit, 4 menit, 6 menit, 8 menit dan 10 menit), menunjukkan bahwa waktu reaksi yang terbaik adalah 10 menit dimana kadar sianida adalah $0,5 \mathrm{mg} / \mathrm{l}$. Penurunan kadar sianida pada percobaan III adalah $98 \%$. Pada percobaan IV bahan kimia yang ditambahkan sama dengan percobaan II, tetapi pHnya dinaikkan yaitu $\mathrm{pH}$ 10,5 dan waktu reaksinya sama dengan percobaan III menunjukkan bahwa waktu reaksi yang terbaik adalah 6 menit, dimana kadar sianidanya adalah $0,4 \mathrm{mg} / \mathrm{l}$ sehingga penurunan kadar sianida adalah $98,6 \%$. Dari keempat percobaan tersebut dapat dilihat bahwa untuk proses oksidasi sianida waktu reaksi yang paling optimum adalah 6 menit pada $\mathrm{pH} 10,5$. Pada proses ini kondisi harus cukup basa, karena apabila tidak cukup basa akan menyebabkan terbentuknya sianogen khlorida (NCL).

Tabel 2. Hasil Oksidasi CNO

\begin{tabular}{|c|c|c|c|c|c|c|}
\hline \multirow[t]{2}{*}{ No } & \multirow[t]{2}{*}{ Percobaan } & \multicolumn{2}{|c|}{$\begin{array}{l}\text { Penambahan bahan } \\
\text { kimia (mg/l) }\end{array}$} & \multirow{2}{*}{$\begin{array}{l}\text { Waktu reaksi } \\
\text { (menit) }\end{array}$} & \multicolumn{2}{|c|}{$\begin{array}{c}\text { Setelah proses oksidasi } \\
\text { CNO }\end{array}$} \\
\hline & & $\mathrm{NaOCl}$ & $\mathrm{H}_{2} \mathrm{SO}_{4}$ & & $\mathrm{pH}$ & $\mathrm{CNO}(\mathrm{mg} / \mathrm{l})$ \\
\hline I & Percobaan I & $\begin{array}{l}123 \\
123 \\
123 \\
123 \\
123 \\
\end{array}$ & $\begin{array}{l}310 \\
310 \\
310 \\
310 \\
310 \\
\end{array}$ & $\begin{array}{c}2 \\
4 \\
7 \\
10 \\
15 \\
\end{array}$ & $\begin{array}{l}8,0 \\
8,0 \\
8,0 \\
8,0 \\
8,0\end{array}$ & $\begin{array}{c}45,0 \\
30,0 \\
21,0 \\
12,0 \\
2,0 \\
\end{array}$ \\
\hline II & Percobaan II & $\begin{array}{l}123 \\
123 \\
123 \\
123 \\
123\end{array}$ & $\begin{array}{l}150 \\
150 \\
150 \\
150 \\
150 \\
\end{array}$ & $\begin{array}{c}5 \\
10 \\
15 \\
25 \\
40 \\
\end{array}$ & $\begin{array}{l}9,5 \\
9,5 \\
9,5 \\
9,5 \\
9,5\end{array}$ & $\begin{array}{c}38,0 \\
29,0 \\
22,5 \\
11,5 \\
1,0\end{array}$ \\
\hline III & Percobaan III & $\begin{array}{l}123 \\
123 \\
123 \\
123 \\
123 \\
\end{array}$ & $\begin{array}{l}0 \\
0 \\
0 \\
0 \\
0 \\
\end{array}$ & $\begin{array}{l}10 \\
20 \\
30 \\
45 \\
60 \\
\end{array}$ & $\begin{array}{l}10,5 \\
10,5 \\
10,5 \\
10,5 \\
10,5 \\
\end{array}$ & $\begin{array}{c}37,5 \\
29,5 \\
22,0 \\
10,0 \\
2,0 \\
\end{array}$ \\
\hline
\end{tabular}


Pada proses oksidasi CNO penambahan $\mathrm{NaOCl}$ dan $\mathrm{H}_{2} \mathrm{SO}_{4}$, seperti terlihat pada Tabel 2, menunjukkan bahwa untuk $\mathrm{pH}=$ 8 dengan waktu reaksi 2 menit, 4 menit, 7 menit, 10 menit, 15 menit, waktu reaksi yang paling baik adalah 15 menit, kadar $\mathrm{CNO}=2 \mathrm{mg} / \mathrm{l}$.Pada percobaan II dengan $\mathrm{pH}=9,5$ dan waktu reaksi 5 menit, 10 menit, 15 menit, 25 menit, 40 menit yang terbaik adalah 40 menit, dimana kadar $\mathrm{CNO}=1,0 \mathrm{mg} / 1$, sedangkan pada $\mathrm{pH}=$ 10,5 waktu reaksi 10 menit, 20 menit, 30 menit, 45 menit, 60 menit waktu reaksi terbaik adalah 60 menit dengan kadar $\mathrm{CNO}=2,0 \mathrm{mg} / \mathrm{l}$. Proses oksidasi CNO yang paling optimum adalah pada $\mathrm{pH}=$ 8,0 dengan waktu reaksi 15 menit, dimana kadar $\mathrm{CNO}=2,0 \mathrm{mg} / \mathrm{l}$. Setelah dilakukan kedua tahapan proses oksidasi, dilakukan proses koagulasi sedimentasi dengan penambahan alum $10 \%$, kemudian effluent disaring. Filtrat darı proses penyaringan dianalisa kadar sianidanya dengan menggunakan AAS hasilnya adalah $0,04 \mathrm{mg} / \mathrm{l}$. Sebelum dibuang dilakukan netralisasi, karena $\mathrm{pH}$ effluent dari proses penyaringan adalah 8,5, dimana $\mathrm{pH}$ ini bahaya terhadap lingkungan.

\section{KESIMPULAN}

1. Proses oksidasi sianida berdasarkan 2 tahapan reaksi :

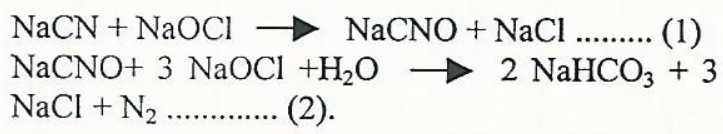

$\mathrm{NaCNO}+3 \mathrm{NaOCl}+\mathrm{H}_{2} \mathrm{O} \longrightarrow 2 \mathrm{NaHCO}_{3}+3$ $\mathrm{NaCl}+\mathrm{N}_{2}$ (2).

Kondisi optimal proses oksidasi sianida adalah $\mathrm{pH}=10,5$ dan waktu reaksi 6 menit, sehingga penurunan kadar sianida $=98,6 \%$.

2. Kondisi optimal proses oksidasi $\mathrm{CNO}$ adalah pada $\mathrm{pH}=8,0$ dan waktu reaksi 15 menit.

3. Kadar sianida pada limbah cair $=30$ $\mathrm{mg} / \mathrm{l}$, setelah dilakukan proses oksidasi, koagulasi sedimentasi dan penyaringan, maka kadar sianidanya menjadi 0,004 mg/l. "Effluent" dapat dibuang ke lingkungan umum, karena pada baku mutu limbah cair industri khususnya industri pelapisan logam kadar sianida maksimum $0,05 \mathrm{mg} / \mathrm{l}$.

\section{DAFTAR PUSTAKA :}

1. Anonymous, 1997, Fundamentals of Industrial Pollution Prevention on Industrial Water Pollution Prevention Technology Part Two, MOIT-JICA, Project on Training in Industrial Pollution.

2. Kazuo Tanaka (1997) Plating and Waste Water Treatment Technology, MOIT JICA, Project on Training in Industrial Pollution.

3. Metcalf \& Eddy Inc, Waste Water Engineering, Treatment, Disposal and Reuse, Third Edition, Mc. Graw-Hill.

4. Studi Pustaka Gambaran Umum Industri Yang Diteliti di Indonesia, Depperindag.

5. Water Treatment Hand Book (1991), Degremont, Sixth Edition, Volume 2. 